\title{
Comparative analysis of four biomarkers in diagnosing premature rupture of membranes and their correlation with onset of labour
}

\author{
Maureen Prativa Tigga*, Sunita Malik
}

\author{
Department of Obstetrics \& Gynaecology, Vardhman Mahavir Medical College \& Safdarjung Hospital, New Delhi, \\ India
}

Received: 25 May 2015

Accepted: 06 June 2015

\author{
*Correspondence: \\ Dr. Maureen Prativa Tigga, \\ E-mail: maureentigga@gmail.com
}

Copyright: $($ ) the author(s), publisher and licensee Medip Academy. This is an open-access article distributed under the terms of the Creative Commons Attribution Non-Commercial License, which permits unrestricted non-commercial use, distribution, and reproduction in any medium, provided the original work is properly cited.

\begin{abstract}
Background: The diagnosis of equivocal cases of premature rupture of membranes (PROM) with traditional methods has been unreliable therefore various biochemical markers have been sought to confirm the same. This study aims to determine the most reliable marker amongst $\beta$ human chorionic gonadotropin ( $\beta$ hCG) $\alpha$ fetoprotein (AFP), prolactin and creatinine in vaginal washing for diagnosing PROM and to establish the correlation between the level of these markers and the onset of labour.

Methods: Fifty pregnant women between 20 and 40 weeks of gestation with history of leaking per vaginum (study group) and an equal number of gestation matched pregnant women without leak (control group) were recruited to the study. All women underwent speculum examination aiming to sample and assay the two markers. The duration from PROM to onset of labour was recorded in the study group. Data was analyzed by student's t-test, receiver operator curve and chi square test.

Results: Vaginal washing concentration of the markers were significantly higher in the study group $(p<0.01)$ thereby rendering them as markers for diagnosing PROM. There was negative correlation coefficient between the levels of markers and duration from PROM to onset labour, denoting early onset of labour in patients with higher levels of markers.

Conclusions: AFP and creatinine were better markers for diagnosing premature rupture of membranes while $\beta$ human chorionic gonadotropin was the better predictor of onset of labour.
\end{abstract}

Keywords: Premature rupture of membranes, $\beta$ human chorionic gonadotropin, $\alpha$ fetoprotein, Prolactin, Creatinine

\section{INTRODUCTION}

Premature rupture of membranes (PROM) is the rupture of fetal membranes before the onset of labour. PROM affects 3 to $18.5 \%$ of all pregnancies and there is no demonstrable cause in most of these cases. ${ }^{1}$

PROM has been a conundrum for the obstetricians and its correct diagnosis is important for implementing gestational age-specific obstetric interventions. PROM is easy to diagnose when the rupture is overt but difficult when the rupture is slight. A timely diagnosis ensures proper intervention thereby improving the maternal and fetal outcomes. On the contrary, a false-positive diagnosis of preterm PROM may lead to unnecessary hospitalization, antibiotics and corticosteroids administration, and induction of labour. The diagnosis of PROM has conventionally relied on patient's history of fluid leakage per vaginum, confirmed by the presence of pooling of amniotic fluid in vagina on speculum examination. The alkaline vaginal $\mathrm{pH}$ detected by nitrazine paper and the presence of ferning pattern after microscopic examination of dried vaginal secretions also aid in diagnosis. However there are drawbacks of these conventional methods. In case of long latent period, amniotic pooling cannot be demonstrated on speculum examination but this does not exclude membrane rupture. Friedman and Mc Elin showed poor reliability of 
nitrazine paper test giving $9.4 \%$ false negative \& $17.4 \%$ false positive result according to their study. ${ }^{2}$

Cytological staining techniques to identify fetal lanugo, fat globules and squamous cells have been relinquished now because they are time- taking and are technically difficult. Similarly, dye instillation which is considered as the gold standard is not the preferred method because it is invasive and dye may affect the fetus adversely.

Amniotic fluid index determination by ultrasonography is still not reliable, because oligohydramnios for any reason cannot be distinguished easily from decreased amniotic fluid as a result of PROM. Therefore false positive and false negative rates are high.

The aforementioned limitations of the conventional testing methods have prompted investigators to seek alternative biochemical markers in amniotic fluid, such as prolactin, ${ }^{3-5}$ alpha-fetoprotein, ${ }^{3,6,7,26} \beta$-subunit of human chorionic gonadotropin, ${ }^{3,7-12}$ fetal fibronectin, ${ }^{6,13,14}$ diamine oxidase, ${ }^{6,15,16}$ lactate, ${ }^{17}$ creatinine, ${ }^{7,18-21}$ urea, ${ }^{17}$ and insulin growth factor binding protein-1. ${ }^{14,15}$ The rationale of assessing these markers stems from their high concentrations in amniotic fluid compared with normal vaginal secretions. The tests are based on the identification in the vaginal washing of one or more of these biochemical markers that are present in the setting of PROM, but absent in women with intact membranes.

$\beta$ hCG is a gycoprotein produced exclusively by syncytiotrophoblasts in the placenta. ${ }^{22}$ It is present in amniotic fluid, as well as maternal blood and urine at a concentration ranging from $2000-70,000 \mathrm{mIU} / \mathrm{ml}^{22}$ Thus a high $\beta$ hCG concentration of in the amniotic fluid renders it to be a possible marker of PROM. Also, it is secreted by the cervical glands and is present at a certain level in vaginal fluid.

Mammalian AFP is a single chain glycoprotein with a molecular mass ranging from $66-72 \mathrm{k} \mathrm{D.} .^{20}$ It is initially synthesized by yolk sac, followed thereafter by fetal liver. After entering the fetal urine it is detected in the amniotic fluid. ${ }^{21}$ The concentration gradient between the fetal plasma AFP and maternal AFP is approximately $150-200$ fold. ${ }^{20}$ Thus a higher concentration of AFP in the amniotic fluid renders it to be a possible marker of PROM.

Prolactin is a single polypeptide chain produced by anterior hypophysis under the control of hypothalamus. ${ }^{22}$ During pregnancy prolactin is produced by the maternal and the fetal hypophysis and the decidua. Higher concentration of prolactin is found in amniotic fluid as prolactin actively participates in the control of amniotic fluid volume and osmolarity. ${ }^{21}$ It has been found that the prolactin level in amniotic fluid is approximately 5-10 times that in maternal circulation. ${ }^{22}$

Creatinine in amniotic fluid is mainly contributed by the fetal urine. ${ }^{26}$ The fetus starts excreting urine into the amniotic fluid at $8^{\text {th }}$ to $11^{\text {th }}$ week of gestation. ${ }^{26}$ The creatinine concentration ranges between 1.5 to $2.0 \mathrm{mg} / \mathrm{dl}$ after 36 weeks till term. ${ }^{26}$

Thus it can be concluded that the mentioned biochemical markers have a high amniotic fluid concentration and can be employed in diagnosing PROM in equivocal cases. The current study is therefore designed to evaluate the clinical reliability of using $\beta$ hCG, AFP, prolactin and creatinine in vaginal washings to diagnose PROM and the correlation between their levels and duration from PROM to onset of labour.

\section{METHODS}

It was a case-control study conducted in Safdarjung Hospital New Delhi. A total of 80 consecutive pregnant women between $20-40$ weeks of gestation, reporting to the antenatal OPD and labour room with history of leaking per vaginum and 50 gestation- matched controls without a history of leaking were screened. Per speculum examination using the Sims speculum was performed in all the subjects. Two patients with frank leaking, indicated by the collection of amniotic fluid on Sims speculum, 25 patients with blood stained or mucoid discharge and 3 patients who were already in labour were excluded. Thus, 50 patients each in study and control groups were enrolled. All the patients had singleton pregnancies with no history of pregnancy- related diseases. Vaginal washings were collected after a written informed consent from all the subjects. Sims speculum was inserted into the vagina and posterior fornix was irrigated with $3 \mathrm{ml}$ of sterile saline using $5 \mathrm{ml}$ syringe. The same syringe was used to aspirate the vaginal washing from the fornix. These washings were transported to the laboratory at room temperature. The samples were centrifuged and stored at -20C until assay. $\beta$ hCG, AFP and prolactin were measured by using the Calbio Inc ELISA kits for the individual proteins and creatinine was measured by using the Jaffe's technique. The enrolled patients in the study group were observed in the labour room for the subsequent onset of labour, which was determined by 3 uterine contractions in 10 minutes on per abdominal examination. ${ }^{27}$ The duration of onset of labour since the occurrence of rupture of membranes was calculated by adding up the leak duration in hours as specified by the patient's history, and the duration of onset of labour. The data were recorded in a predesigned proforma.

Statistical analysis: The continuous data were compared using the Student $\mathrm{t}$ test or Mann- Whitney $\mathrm{U}$ test as applicable. SPSS was used. The receiver operating characteristics (ROC) curve was drawn to define the best cut off value of vaginal washings $\beta \mathrm{hCG}$, AFP, prolactin and creatinine levels to diagnose PROM. The sensitivity, specificity, positive and negative predictive values (PPV and NPV) were calculated using the $2 \times 2$ contingency table. SPSS version 17.0 was used for statistical analysis. A $p$ value of $<0.05$ was considered as significant. 


\section{RESULTS}

The demographic data for both groups are presented in Table 1.The gestational age and parity between the two groups were comparable. The mean values of the four markers were higher in the study group than in the control group: $\beta$ hCG: $49.17 \pm 11.87$ versus $29.48 \pm 9.41$ $\mathrm{m} \mathrm{IU} / \mathrm{ml}$; AFP: $57.08 \pm 7.25$ versus $22.58 \pm 10.64 \mathrm{ng} / \mathrm{ml}$; prolactin: $30.42 \pm 6.60$ versus $19.06 \pm 5.55 \mathrm{mg} / \mathrm{ml}$, and creatinine: $0.26 \pm 0.0663$ versus $0.09 \pm 0.0414 \mathrm{mg} / \mathrm{ml}$ (Table 1).

Table 1: Demographic data and the mean level of each marker in patients of study and control group.

\begin{tabular}{|c|c|c|c|}
\hline Parameters & $\begin{array}{l}\text { Study } \\
\text { Group }\end{array}$ & $\begin{array}{l}\text { Control } \\
\text { Group }\end{array}$ & P Value \\
\hline $\begin{array}{l}\text { Mean Gestational } \\
\text { age at sampling in } \\
\text { weeks }\end{array}$ & $\begin{array}{l}35.55 \pm \\
3.84\end{array}$ & $\begin{array}{l}36.67 \pm \\
3.84\end{array}$ & 0.586 \\
\hline Parity & $\begin{array}{l}0.88 \pm \\
3.92\end{array}$ & $\begin{array}{l}0.84 \pm \\
4.00\end{array}$ & 0.837 \\
\hline $\begin{array}{l}\text { Mean } \beta \text { hCG m } \\
\text { IU/ml }\end{array}$ & $\begin{array}{l}49.17 \pm \\
11.87\end{array}$ & $\begin{array}{l}29.48 \pm \\
9.41\end{array}$ & 0.000 \\
\hline Mean AFP ng/ml & $\begin{array}{l}57.08 \pm \\
7.25\end{array}$ & $\begin{array}{l}22.58 \pm \\
10.64\end{array}$ & 0.000 \\
\hline $\begin{array}{l}\text { Mean Prolactin } \\
\mathrm{mg} / \mathrm{ml}\end{array}$ & $\begin{array}{l}30.42 \pm \\
6.60\end{array}$ & $\begin{array}{l}19.06 \pm \\
5.55\end{array}$ & 0.000 \\
\hline $\begin{array}{l}\text { Mean creatinine } \\
\mathrm{mg} / \mathrm{ml}\end{array}$ & $\begin{array}{l}0.26 \pm \\
0.0663\end{array}$ & $\begin{array}{l}0.09 \pm \\
0.0414\end{array}$ & 0.000 \\
\hline $\begin{array}{l}\text { Mean duration of } \\
\text { PROM (hours) }\end{array}$ & $\begin{array}{l}20.04 \pm \\
23.8\end{array}$ & & \\
\hline $\begin{array}{l}\text { Mean duration from } \\
\text { PROM to onset of } \\
\text { labour (hours) }\end{array}$ & $\begin{array}{l}36.64 \pm \\
38.4\end{array}$ & & \\
\hline
\end{tabular}

Receiver operator curve analysis indicates the diagnostic performance of the four markers (fig.1). The area under the curve was 0.855 for $\beta$ hCG; 0.931 for AFP; 0.863 for prolactin and 0.900 for creatinine $(\mathrm{p}=0.000)$. The best cut off values to diagnose PROM were as follows: $37.06 \mathrm{~m}$ $\mathrm{IU} / \mathrm{ml}$ for $\beta \mathrm{hCG} ; 45.80 \mathrm{ng} / \mathrm{ml}$ for AFP; $23.56 \mathrm{mg} / \mathrm{ml}$ for prolactin; and $0.1641 \mathrm{mg} / \mathrm{ml}$ for creatinine. The sensitivity, specificity, PPV, NPV and efficiency were: $84 \%, 68 \%, 72.41 \%, 80.95 \%$ \& $76 \%$ for $\beta \mathrm{hCG}$; $98 \%$, $94 \%, 94.23 \%, 97.92 \%$, \& 96\% for AFP; 78\%, 68\%, $70.9 \%, 75.56 \% \& 73 \%$ for prolactin and $100 \%, 92 \%$, $92.59 \%, 100 \%$ for creatinine. Statistical information clearly indicated that amongst all the markers AFP \& creatinine had better diagnostic performance (Table 2).

In our study, 12 patients had the duration of PROM $>24$ hours and 38 patients had the duration of PROM <24 hours. The mean duration of PROM was found to be $20.64 \pm 23.8$ hours while the mean duration from PROM to onset of labour was $38.64 \pm 38.4$ hours (Table 1 ). The correlation coefficient between the level of markers and the duration from PROM to onset of labour were -0.910 for $\beta \mathrm{hCG},-0.770$ for AFP, -0.745 for prolactin and -0.678 for creatinine respectively $(\mathrm{p}=0.000)$. This denoted that the patients with higher levels of markers had earlier onset of labour. Out of the four markers, $\beta$ hCG was a better predictor of onset of labour. The level of the markers and the duration of leaking (PROM) also had a negative association with correlation coefficients of 0.728 for $\beta$ hCG, -0.701 for AFP, -0.869 for prolactin \& 0.627 for creatinine $(\mathrm{p}=0.000)$. (Table 3$)$.

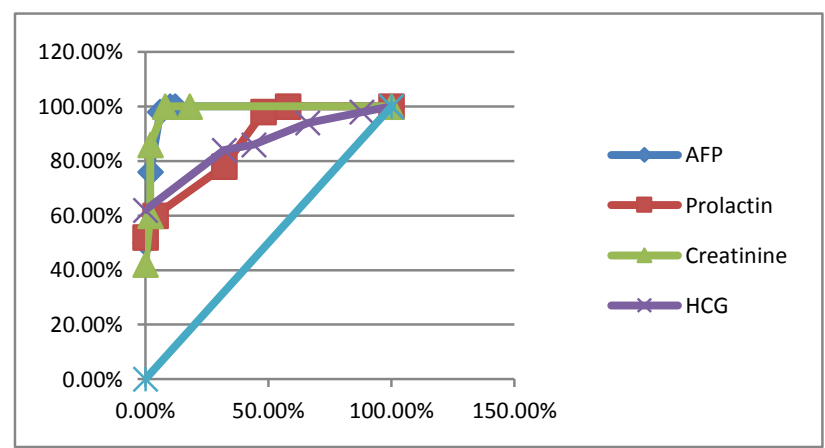

Figure 1: Receiver operating curve for the markers.

Table 2: Diagnostic performance of individual markers.

\begin{tabular}{|llllllll|}
\hline Marker & Cut off & sensitivity & specificity & $\begin{array}{l}\text { Area } \\
\text { under } \\
\text { curve }\end{array}$ & PPV & NPV & Efficiency \\
\hline$\beta \mathrm{hCG}$ & $\begin{array}{l}37.06 \\
\mathrm{mIU} / \mathrm{ml}\end{array}$ & $84 \%$ & $68 \%$ & 0.855 & $80.95 \%$ & $72.41 \%$ & $76 \%$ \\
\hline AFP & $\begin{array}{l}45.80 \\
\mathrm{ng} / \mathrm{ml}\end{array}$ & $94 \%$ & $98 \%$ & 0.931 & $97.92 \%$ & $94.23 \%$ & $96 \%$ \\
\hline Prolactin & $\begin{array}{l}23.56 \\
\mathrm{mg} / \mathrm{ml}\end{array}$ & $68 \%$ & $78 \%$ & 0.863 & $75.53 \%$ & $70.91 \%$ & $73 \%$ \\
\hline Creatinine & $\begin{array}{l}0.1641 \\
\mathrm{mg} / \mathrm{ml}\end{array}$ & $100 \%$ & $92 \%$ & 0.900 & $92.59 \%$ & $100 \%$ & $96 \%$ \\
\hline
\end{tabular}


Table 3: Correlation of vaginal washing $\beta$ hCG \& creatinine levels with duration of PROM and duration of onset of labour.

\begin{tabular}{|llll|}
\hline Markers & $\begin{array}{l}\text { Duration } \\
\text { of PROM }\end{array}$ & $\begin{array}{l}\text { Duration } \\
\text { from PROM } \\
\text { to onset of } \\
\text { labour }\end{array}$ & $\begin{array}{l}\text { p } \\
\text { value }\end{array}$ \\
\hline $\begin{array}{l}\text { Correlation } \\
\text { coefficient } \\
(\beta h C G)\end{array}$ & -0.728 & -0.910 & 0.0000 \\
\hline $\begin{array}{l}\text { Correlation } \\
\text { coefficient } \\
\text { (AFP) }\end{array}$ & -0.701 & -0.770 & 0.000 \\
\hline $\begin{array}{l}\text { Correlation } \\
\text { coefficient } \\
\text { (Prolactin) }\end{array}$ & -0.869 & -0.745 & 0.000 \\
\hline $\begin{array}{l}\text { Correlation } \\
\text { coefficient } \\
\text { (creatinine) }\end{array}$ & -0.627 & -0.678 & 0.000 \\
\hline
\end{tabular}

\section{DISCUSSION}

PROM as an obstetrical entity can have serious outcomes so its accurate diagnosis is of great importance. PROM can lead to infectious morbidity such as chorioamnionitis and imminent term or preterm labour. Patient's history alone is not always reliable and with conventional diagnostic techniques, some cases still remain unconfirmed. Therefore studies have been conducted to test the diagnostic accuracy of alternative biochemical markers for PROM.

In our study we sought to establish the diagnostic accuracy of $\beta \mathrm{hCG}$, AFP, prolactin and creatinine as markers of PROM. We found that the levels of the mentioned markers were significantly higher in the patients with PROM in comparison to those without PROM.

The clinical application of $\beta$ hCG in diagnosing PROM has been supported by many investigators. ${ }^{3,7-12}$ Our study demonstrated $\beta$ hCG cut off value of $37.06 \mathrm{mIU} / \mathrm{ml}$ and the sensitivity, specificity, PPV,NPV and efficiency of $84 \%, 68 \%, 72.41 \%, 80.95 \%$ \& $76 \%$ respectively. This observation was similar to that demonstrated by Shahin et $\mathrm{al}^{3}$.

AFP was demonstrated to be a reliable indicator of PROM with a very high diagnostic performance. The sensitivity, specificity, positive predictive value, negative predictive value and efficiency were found to be $98 \%, 94 \%, 94.23 \%$, $97.92 \%$, and $96 \%$ respectively. Our results were quite similar to that demonstrated by Shahin et al who reported sensitivity, specificity, positive predictive value, negative predictive value and accuracy of $94 \%$ each. ${ }^{3}$ Similar findings with a high diagnostic performance were also reported by $\mathrm{Ni}$ et al from China in $2003 .{ }^{7}$

Prolactin was reported to have an average diagnostic performance in our study with a cut off value of
$23.56 \mathrm{mg} / \mathrm{ml}$. It has been found that the prolactin level in amniotic fluid is approximately 5-10 times that in maternal circulation. ${ }^{25}$ However with advancing gestation the fetal kidneys begin degradation of prolactin and also there is a decline in the decidual secretion of prolactin. Thus in comparison to the other marker like AFP, prolactin does not have a steady elevated concentration and therefore it exhibits lower diagnostic accuracy.

Creatinine was reported to be a good indicator for PROM with $100 \%$ sensitivity, 92\% specificity, $92.59 \%$ PPV, $100 \%$ NPV and $96 \%$ efficiency. This was almost similar to that shown by the other investigators like Zanjani et $\mathrm{al}^{18}$, Sekhavat et $\mathrm{al}^{19} \&$ Kafali et al ${ }^{21}$. Creatinine in amniotic fluid is mainly contributed by the fetal urine and since its level remains constantly high in the amniotic fluid till term it exhibits a very high diagnostic performance.

The comparative evaluation of the 4 markers in our study demonstrates that AFP \& creatinine were more reliable markers of PROM. Highest sensitivity was reported for creatinine which was $100 \%$ while AFP had $98 \%$ sensitivity. The specificity was highest for AFP which was $94 \%$ followed by creatinine which was $92 \%$. The NPV for creatinine was found to be $100 \%$ so if no creatinine was found positive in the vaginal washings one need not doubt about any risk of PROM.

Another facet of our study was to find the correlation between the levels of markers with the duration of PROM and the interval between occurrence of PROM and onset of labour. A negative correlation was observed between the levels of the markers and the duration of PROM, thereby indicating that the patients with prolonged leaking had low levels of these markers (Table 3). This was possibly because over a period of time these markers got washed off and the vaginal washings yielded lower values. The correlation coefficient between the levels of markers and the duration from PROM to onset of labour also showed negative values (Table 3 ). This clearly implicated that in patients with a higher level of markers the duration of onset of labour was less, which means that those patients went into labour early. This aspect of predicting labour onset helps the obstetrician to take appropriate measures to manage PROM, being mindful of the time available as shown by the markers.

Another observation was that though the levels of markers were lower in patients with prolonged leaking (PROM >24 hours) as compared to those with PROM $<24$ hours, but the levels were significantly higher in those without PROM. Thus it is inferred that the aforementioned markers are reliable for diagnosing PROM as well as their levels could be used to predict the onset of labour in patients.

Currently, AFP finds application for multifarious purposes and is used as tumour marker, triple test screening for Down's syndrome and neural tube defects, 
and is often available for daily assay in the tertiary care centres. As there is no need for extra equipment and reagent, introduction of this method into routine use is feasible and practical. Creatinine is a rapid, cheap and easily available test used for various purposes and since it has a high diagnostic performance it can be used particularly as an adjunctive test in equivocal cases of PROM. The best part about creatinine is that it is available even in the district health care centres and is cost effective thus making it an overall ideal marker for PROM. On the other hand $\beta \mathrm{hCG}$ is expensive and not easily available however it turned out to be a better predictor of onset of labour. Also, during the study we found that the patients were compliant with method of sample collection and readily accepted this non invasive technique and therefore vaginal washing AFP and creatinine estimation can be employed as a reliable method for diagnosing PROM.

\section{CONCLUSION}

AFP was the most suitable marker for the diagnosis of PROM followed by creatinine which was not far behind and can be regarded equally reliable. Creatinine estimation is a rapid, cheap and easily available test. This remunerative aspect of creatinine and its availability even in the district health care centres makes it an overall ideal marker for PROM. Women with higher levels of $\beta \mathrm{hCG}$ had earlier onset of labour and it was demonstrated as the best predictor for onset of labour.

Funding: No funding sources Conflict of interest: None declared

Ethical approval: The study was approved by the Institutional Ethics Committee

\section{REFERENCES}

1. John S, Lin TS, Chervenak FA. Progress in Obstetrics \& Gynaecology. $18^{\text {th }}$ edition : Churchill Livingstone, 2008; 203-222.

2. Friedman ML, McElin TW. Diagnosis of ruptured fetal membranes. Clinical study and review of the literature. Am J Obstet Gynecol. 1969;104:544-50.

3. Shahin M, Raslan H. Comparative study of three amniotic fluid markers in premature rupture of membranes: prolactin, beta subunit of human chorionic gonadotropin, and alpha-fetoprotein. Gynecol Obstet Invest. 2006;63:195-199.

4. Kariman N, Hedayati M, AlaviMajd Sh. The diagnostic power of cervico-vaginal fluid prolactin in the diagnosis of premature rupture of membranes. Iran Red Crescent Med J. 2012;14(9):541-8.

5. Buyukbayrak EE, Turan C, Unal O, Dansuk R, Cengizoğlu. Diagnostic power of the vaginal washing-fluid prolactin assay as an alternative method for the diagnosis of premature rupture of membranes. J Matern Fetal Neonatal Med. 2004;15:120-5.
6. Gaucherand P. Guibaus S, Awada A, Rudigoz RC. Comparative study of three amniotic fluid markers in premature rupture of membranes: fetal fibronectin, $\alpha$ fetoprotein, diamino-oxydase. Acta Obstet Gynecol Scand. 1995;74:118-21.

7. Li HY, Chang TS. Vaginal fluid creatinine, human chorionic gonadotropin and alpha fetoprotein levels for detecting premature rupture of membranes. Zhonghua Yi Xue Za Zhi (Taipei). 2000;63:686-90.

8. Esim E, Turan C, Unal O, Dansuk R, Cengizglu B. Diagnosis of premature rupture of membranes by identification of beta-hCG in vaginal washing fluid. J Obstet Gynecol Reprod Biol. 2003;107:37-40.

9. Kim YH, Park YW, Kwon HS, Kwon JY, Kim BJ. Vaginal fluid beta-human chorionic gonadotropin level in the diagnosis of premature rupture of membranes. Acta Obstet Gynecol Scand. 2005;84:802-8.

10. Mangano B, Diani F, Faccini G, Zatti N, Zardini E. Proposal of a new test for the diagnosis of PROM based on the determination of $\beta$ hCG in the washing fluid of the posterior vaginal fornix. Minerva Ginecol. 2000;52(5):185-8.

11. Kariman NS, Jafari E, Amiri Moghadam HR, Alavi Majd H, Mortazavi M. Comparing the diagnostic power of qualitative and quantitative measurements of $\beta$-hCG in cervicovaginal washing-fluid for the diagnosis of PROM. J Repro Infertil. 2007;8(1):97.

12. Cooper AL, Vermillion ST, Soper DE. Qualitative human chorionic gonadotropin testing of cervicovaginal washing for the detection of preterm premature rupture of membranes. Am J Obstet Gynecol. 2004;191(2):593-6.

13. Lockwood CJ, Senyei AE, Dische MR, Casal D, Shah KD, Thung SN, et al. Fetal fibronectin in cervical and vaginal secretions defines a patient population at high risk for preterm delivery. N Engl J Med. 1991;325:669-674.

14. Guibourdenche J, Luton D, Andre E, Noel M, Pourquet D. Rapid detection of insulin like growth factor-binding protein-1 and foetal fibronectin in cervico-vaginal secretions to diagnose premature membrane rupture. Ann Clin Biochem. 1999;36:3889.

15. Gaucherand P, Salle B, Sergeant P, Guibaud S, Brun $\mathrm{J}$, Bizollon CA, et al. Comparative study of three vaginal markers of the premature rupture of membranes. Insulin like growth factor binding protein1, diamine oxidase, and $\mathrm{pH}$. Acta Obstet Gynecol Scand. 1997;76:536-40.

16. Elmfors B, Tryding N, Tufvesson G. The diagnosis of ruptured fetal membrane by measurement of the diamine oxidase (DAO) activity in vaginal fluid. J Obstet Gynaecol Br Commonw. 1974;81:361-2.

17. Wiberg-Itzel E, Cnattingius S, Nordstrom L. Lactate determination in vaginal fluids: a new method in the diagnosis of prelabour rupture of membranes. $\mathrm{Br} \mathrm{J}$ Obstet Gynaecol. 2005;112:754-8. 
18. Zanjani MS, Haghighi L. Vaginal fluid creatinine for the detection of premature rupture of membranes. J Obstet Gynaecol Res. 2012;38(3):505-8.

19. Sekhavat L, Firouzabadi RD, MojiriP. Practicability of vaginal washing fluid creatinine level in detecting premature rupture of membranes. Arch Gynecol Obstet. 2012;286(1):25-8.

20. Gurbuz A, Karateke A, Ozturkmen M, Kabaca C. Vaginal fluid creatinine in premature rupture of membranes. Int J Gynaecol Obstet. 2004;85:270-1.

21. Kafali H, Oksuzler C. Vaginal fluid urea and creatinine in diagnosis of premature rupture of membranes. Arch Gynecol Obstet. 2007;275:157-60.

22. Kletzy OA, Rossman F, Bertolli SI, Platt LD, Mishell DR. Dynamics of $\beta$ hCG Prolactin and growth hormone in serum \& amniotic fluid throughout normal human pregnancy. Am J Obstet Gynaecol. 1995;15:878-84.

23. Mizejewski GJ. Levels of alpha fetoprotein during pregnancy and early infancy in Normal and diseased states. Obstet Gynecol Survey. 2003;58:804-26.

24. Oliviera FR, Barros EG, Magalhaes JA. Biochemical profile of amniotic fluid for the assessment of fetal and renal development. Bras J Med Biol Res. 2002;35:215-22.

25. Schenger JG, Ben David M, Polishukuz A. Prolactin in normal pregnancy relationship Of maternal fetal and amniotic fluid levels. Am J Obstet Gynaecol. 1975; $123: 834$.

26. Ni CY, Jia WX, Yi WM, Feng LH, Yu LZ. Practicability of using vaginal fluid marker in detecting premature rupture of membranes. Ann Clin Biochem. 2003;40:542-45.

27. Normal labour and delivery. In: Cunningham FG, Leveno KJ, Bloom SL,Hauth JC, Rouse DJ, Spong CY (eds). Williams Obstetrics. 23 ${ }^{\text {rd }}$ ed. New Delhi: Mc Graw Hill, 2010; 374- 409.

Cite this article as: Tigga MP, Malik S.

Comparative analysis of four biomarkers in diagnosing premature rupture of membranes and their correlation with onset of labour. Int J Reprod Contracept Obstet Gynecol 2015;4:1070-5. 